\title{
Towards Ensuring a Greater Global Uniformity and Standards in Higher Education
}

\author{
Adhikarla Suryanarayana Rao \\ Department of Biotechnology, Bharathidasan University, Tiruchirappalli, India \\ Email address: \\ asraobio@gmail.com \\ To cite this article: \\ Adhikarla Suryanarayana Rao. Towards Ensuring a Greater Global Uniformity and Standards in Higher Education. International Journal of \\ Education, Culture and Society. Vol. 5, No. 6, 2020, pp. 141-149. doi: 10.11648/j.ijecs.20200506.15
}

Received: November 27, 2020; Accepted: December 25, 2020; Published: December 31, 2020

\begin{abstract}
The article emphasizes to make due attempts to compare and contrast the various parameters pertaining to the running of different educational programs. And accordingly arrive at a consensus to follow as much uniformity as possible and ensure higher standards and reduce the gaps in educational standards. This viewpoint needs to be reflected at the global, national and provincial level. Types and variations are discussed with respect to several parameters Viz; salaries and allowances of teachers, academic calendar patterns, course contents and description, examination patterns, work load norms, duration of various programs, students assessment in both course study and in research component. Need for unbiased treatment of course topics, adequate time for students in various exams, supplementary teaching methods, easy access to fullfledged library-bibliotheque facilities, teacher-student-administrative staff ratio and of increasing the duration of the degree programs to make the students more eligible of higher studies and career placements and responsible citizens has been emphasized. Further, the need to critically analyze the intake of students in various programs and disciplines, teaching methodology, requirement of manpower, need for collaborations with industries \& international institutes -both public and private- is explained and emphasised to run the educational programs. UN and its organizations should seriously contribute to achieve uniformity \& high standards and ensure due international agreements and financial aid.
\end{abstract}

Keywords: Teachers Salaries, Academic Calendar Patterns, Instruction Methods, Work Load, Assessment of Exams, Industry \& International Collaborations, Greater Uniformity

\section{Introduction and Background}

It is a matter of common knowledge that Education and Science \& Technology are two vital inputs for the development and welfare of every society and every nation. Of course, it is not possible for every society and nation to be equally prosperous. However, no society and nation should suffer because of backwardness and poverty but enjoy a decent standard of living. Hence, the teaching-learning situation and policies in Education and Science \& Technology must be viewed from different angles. Not every nation can become a superpower. Protection of nations and maintaining peace is the duty of the UN and its associated organizations. Educational institutions can only inculcate values, impart knowledge, and train the manpower.

The subject of Education and Science \& Technology is too vast and varied across the globe. Nations differ in their economic status, degree of backwardness, population and availability of resources. Further, knowledge is imparted at various levels -Schools-Colleges--Universities-Research Institutes. The latter three can be professional, technical, and non-technical. And all these categories of institutes may belong to the public sector or the private sector. Hence, a single article or a single author cannot cover the entire spectrum. An attempt has been made to discuss different parameters and suggest or trigger in others to take measures and policies to ensure uniformity across the globe and to uphold the academic fraternity and standards. The focus is primarily on higher education (Excluding professional \& technical education like Medical, engineering, etc.) in the faculty of arts \&humanities and sciences and agriculture, in which the author has nearly four decades of experience both as a student and teacher and observing the scenarios both in India and abroad. However, some concepts discussed are also applicable to a good extent to other fields. 


\section{Analysis of Different Parameters and Nomenclature}

\subsection{Pay \& Perks and Self Esteem of Teachers}

The prestige of a teacher should be maintained, and a decent living for them has to be ensured. After taking into consideration the PPP (Purchase Power Parity) and tax structure, teachers at all levels and all over the globe should be paid uniformly -not much variations in any case [1-3]. Not only salaries but other perks like medical \& social security, residential housing during the tenure of the service etc, and more importantly, the retirement age must be uniform or more or less uniform in all nations and within the nations across the globe. Governments should ensure that the self-esteem of teachers is maintained and they get due dignity and protection Vis-a Vis personnel employed in other sectors. Of course, with all the above ensured, it is essential that governments make judicious employment of teachers and can duly assess them and constantly monitor both by relevant evaluators, parents, and the general public.

\subsection{Academic Calendar}

Historically, depending on the nation and depending on the time period, four patterns of academic calendar were/are there -quarterly -Trimester-semester -Annual. Presently the annual system is exceptional, and the other three systems are more common, of which semester system being apparently the most followed by trimester. (During British India annual system - that is, only one final exam at the end of every year and the absolute number of marks obtained by the student were mentioned in the official records -was followed. and this system continued even Post-Independence for a long time. Reference to British has been made in the manuscript a few times for the reason that British had a vast empire for a long time across the world. So it is quite likely that the same system as India was following during British time might have been there/is there in several other countries too. India and other countries have subsequently started following the American system of grades and grade point system and CBCS (choice based credit system) extensively) [4-14].

So what academic calendar should be opted for? Though semester system is being largely followed, there is a considerable division of opinion as many still prefer the trimester over the semester system. Hence need to be debated.

\subsection{Work Load}

Across the nations, Government holidays and other categories of leave that can be legitimately availed by students and teachers vary a lot. Hence, in view of the above mentioned academic calendar patterns and in view of variations across the nations in the number of mandatory working days per year and mandatory working hours per day, due standardization is required for the curriculum to be completed with due justice \& satisfactory learning outcomes and for the teachers to render services other than teaching as effectively in their respective institutes. Definitions should be unambiguous and, if required, duly explained. Say "instruction hours/ instruction days should only mean hours/days on which lectures have been delivered by the teacher -that is the number of hours /days for which students have been taught in person. This number should exclude the days a) on which examinations are conducted b) seminars are presented by students c) study/exam preparatory holidays and d) any other activities like attending conferences etc. The entire curriculum must be taught to the required depth exclusively by the teacher(s), and students should no way be penalized in this regard by insisting them to give seminars or assignments to complete the curriculum. Students abilities in this regard may be separately assessed.

Even a casual Google survey and author's individual experience as well indicate that quarter, trimester, and semester may constitute/can vary from 10 weeks, 12-14 weeks, and 15-18 weeks, respectively. In other words, in a five-day week (of 8 hours /day) the above amounts to a maximum of 200 days, 210 days, and 180 days respectively. So what should be followed for facilitating the students to achieve better learning outcomes? Teaching and learning should be duly spread over a reasonable period of time. Author feels that maximum time gives a better outcome with less stress to master the curriculum. Hence, 200 days -that is 100 days per semester (20 weeks) — may be thought of! But 20 weeks is not so common. Rather 18 weeks (90 days per semester) is common, which is less than the quarter and trimester systems -keeping all other conditions as constant. This aspect needs to be debated. In the case of a six-day week being followed accordingly, the adjustment has to be made. In a five-day week, the day starts early, which may or may not be difficult for students, teachers and administrative staff in many places. The number of mandatory working hours of the institutes must be adequate to give some gap for the students between two periods and some time for discussion among themselves and /or with the teacher. Another point to be taken into consideration while adjusting is the duration of the lecture/instruction hour. Even this varies from 45 minutes to one and a half hours. However, the concept of one-hour duration has gained more acceptance, particularly after the credit/grade point system has been introduced, with one credit hour being defined as one hour of instruction. Students feedback needs to be solicited and accordingly decide both the instruction time and the time for interaction for clarifying doubts. In addition to the interaction time during/after instruction hour, teachers should be available for interaction outside the instruction hours and more particularly before the exams period where teachers have to be available for a longer time. Accordingly, students should have free time during the working hours of the institute.

A general impression among both students and teachers particularly those concerned with pedagogy- is a student may require at least 2-3 hours time per every one hour of lecture 
delivered to understand and /or memorize and face the exams. Hence, students should not be overloaded, and their total workload duly decided. The entire purpose of teaching /education fails if the knowledge imparted does not enter into the long term memory of the students. Hence, the author feels not more than 12 hours of theory instruction including 3-4 hours of practicals /experiments. In case researchcommitment is more then the teaching laod needs to be accordingly reduced. In some ocutries one semester is made completely free of teaching responsibilities for the fauclty to concentrate on research [15-19].

\subsection{Research Component}

Every nation cannot -rather should not -blindly imitate at least in toto the system and attitudes prevailing in prosperous and well-developed countries. Every nation and every province in the nation should know its limitations and accordingly strike a balance. Taking India as an example to drive a message. Right from British India till along time after independence, there was no research component (dissertation/thesis) during Master's program. (Even today, one can find such a situation in some places). But after some time, India has adopted the American/ Western system of a research component in the final semester of the Master's program. Even this system has variations as some carry out both some course work and research work simultaneously in the same semester. When the institutes face resource crunch even for giving due hand son experience as per the curriculum, how is it possible to support them -that too in large numbers - for research activity?? More relevant is the fact that the number of students are enormous. Hence, alternatives have to be critically thought and explored. Possible alternatives are to eliminate the project work/research component in Master's program a) and divert whatever the time and money available to enhance students hands-on experience as per the curriculum b) and substitute the research component with some advanced courses and other courses to enrich their subject knowledge and/or to increase their job prospects in different sectors, help them in clearing exams which can secure scholarships and thereby increase the prospects for higher education abroad and in more reputed institutes. In this regard, a few specific suggestions are to train them in general GRE (Graduate Record Exam), subject GRE, TOEFL (Test of English as Foreign Language), IELTS (International English Language Testing System and any foreign language of students choice.

In case the research component has to be included, possible alternatives are i)) to have the research component only in a few ii) to have collaborations with industries, hospitals etc, and make the students do their research there. This will also help them in securing jobs in their respective industries. For the rest above mentioned, "a" and/or 'b" may be followed. In fact, many students may not prefer to have a research component as they may wish to diversify their careers, and so accordingly, they may require additional courses or training in the concerned sector. The research component problem may not be as serious for the students in the faculty of arts and humanities as they do not require so much money as in science.

\subsection{Types and Duration of Course Programmes}

While many programs are there, the most common are three year and four-year bachelors and one year or 2 Years Master's program. (Duration of $\mathrm{Ph}$. D. programs is variable unfortunately - and needs to be discussed separately). Due to ideas flowing from different places and /or from people at the helm of policy affairs, in addition to the above programs, a limited number of five year integrated Master's programs soon after completing the school education and integrated $\mathrm{Ph}$. D. program after completing bachelor's degree have been started (As mentioned above the duration of even independent $\mathrm{Ph}$. D. program is variable. Hence, the duration of integrated $\mathrm{Ph}$. D. programs also is variable). Neither all students nor all students can afford these relatively novel programs, and the relative advantages and disadvantages of these novel programs Vis-a Vis regular programs running for a long time needs to be debated and create due awareness among the students, parents, and the general public. From the author's experience with students, parents, and colleagues, a few are mentioned below: a) Many students and parents have the ambition of sending their children abroad for higher studies. Sixteen years of education -that is - twelve years of schooling plus four years of Bachelor's degree is the requirement to get admissions into most foreign institutions. Hence, both students and parents do not prefer an integrated five years program, which makes the total duration of seventeen years. In other words, the ambition of the parents/students going abroad has been delayed by an year. So either they do not prefer this system or they wish a pullout option with a Bachelor's Degree after four years in the five-year integrated program. Because of the same logic, many do not prefer to pursue a 3 years Bachelor's program followed by a two-year Master's program, as this also amounts to 17 years of education. However, a three year BSc is preferred by a large number of people who want to go for jobs and to pursue courses and exams relevant to their career which they are aspiring b) In case of integrated $\mathrm{Ph}$. D. students are again in a dilemma because of variations and uncertainties. While some may give an option to pull out in between with a Master's degree some may confer only a Ph. $\mathrm{D}$. at the end. So the student is BSc-PhD with no Master's qualification. And the time within which they can get the $\mathrm{Ph}$. D. is uncertain. Even where there is an option to pull out in between with a Master's degree, the time when they can pull out varies in different institutes or even within the same institute depending on the research supervisor in view of the flexibility of rules and regulations governing the program.

\subsection{Ph.D Program}

$\mathrm{Ph}$. D. programs have been discussed long back in a few articles in nature which have been duly appraised in the editorial [19]. It would be useful if the concerned authors update them. Many decent jobs, even lucrative jobs and jobs 
to sustain oneself, can be secured with as much effort in sectors other than academics that too at an earlier age. So both students and parents think / should think as to why Ph. D. should be pursued? Only those who have the real aptitude for higher education \& research and want to become an academician should opt for a Ph. D. Further, they should not have any constraints for pursuing. Can everyone or every institute afford Ph. D. programs? How many should pursue and how many an institute can afford? Funds and expertise are two major constraints. Over and above, there is the constraint to accommodate these Ph. D.'s suitably. Very often, they do not have any other option than to pursue Post-Doc for varying periods of time $[21,22]$. An arduous task. Both students and the institutes and above all the governments must be clear about the nature of research and the task involved in the accomplishment of objectives/goals in scientific research. It is only because of so many limitations nations have to depend on imports of various goods and services.

In science, objectives /goals have three dimensions -Time, Capital, and Manpower. To achieve the objective /goal, how much time, money, and manpower is required has to be critically analyzed. Say the development of a drug or a vaccine requires even governments are not able to support the activity but the goals are run by the corporates. So how can one expect an institute or an university to achieve the objective /goal? Long term continuity of work and funding and teamwork is not possible in all universities -barring exceptions. Useful discoveries are more important in the immediate time span than exciting discoveries. Backward nations need useful discoveries and solutions for solving local problems. A nation can offer Ph. D. in universities, research institutes, and colleges. And these can be under provincial/state control or Federal/central government control. So what should be the role of Ph. D.'s need to be determined before the intake? Critical planning is required to decide on their numbers and the disciplines and the topics of research in which they can be accommodated. Indiscriminate bringing of them is detrimental. A few suggestions to tide over the limitations and pressures: a) Ph. D.'s may work on such problems of local/provincial relevance for which money and expertise may not be a serious limitation $b$ ) to enter into collaborations with various industries /corporates where the students can do Ph. D. (research component) to the industrial requirements. This will also increase their job prospects. Alternatively, industries/ corporate may suggest a plan of work to the concerned researchers in the universities/research institutes/colleges to be carried out by a Ph. D. student. They may fund the same as well c) Students after Masters may take up a job at a lower level in the industries and during the on the job training and work turned out in this position may be submitted for a $\mathrm{Ph}$. D. to an university with which the industry has an agreement d) to enter into collaborations with International institutes either within the nation or outside where students can do their Ph. D. either wholly or partly c) as mentioned above the funds problem is less in case of faculty of arts and humanities. However, even they are advised to work on problems of provincial and national relevance.

Irrespective of the system followed, the students must be able to complete their $\mathrm{Ph}$. D. within the prescribed period as per the rules of the degree conferring institutes. A little delay can be understood, but any undue delay is unfair. In India which has a very large education system - it is legitimately possible to get a $\mathrm{Ph}$. D. in 8 years of time after finishing 12 years of schooling. That is $3+2+3$ - prescribed duration for Bachelors, Masters, and $\mathrm{Ph}$. D. respectively. Of course, in spite of this stipulation, not many may get in this time --as discretionary powers of the Research supervisors and flaw in the rules of the concerned institutes--allow them to retain the $\mathrm{Ph}$. D. candidate unduly for much more time. Not only in India, but it is also possible to get a $\mathrm{Ph}$. D. in three years -a little more time at the most-- even in good institutes abroad. And getting in 4 years is possible in so many developed countries - that is either $3+2+4$ or $4+1+4$ for Bachelors, Master's and $\mathrm{Ph}$. D. respectively. Deviations, of course, exist there as well. Any further work can be carried out by the succeeding Ph. D. student. No need for retaining the same student unduly for a long time.

\subsection{Need for Slightly Increasing the Duration of Bachelors and Master's Program}

Over a period of time, educational pressures have increased, making some of the policymakers feel the necessity of adding additional courses in the career and placement interest of the candidates and candidates responsibility towards the society/nation. Some policymakers feel that with the present time at their disposal it is difficult to do so. Hence, a need for slightly increasing the duration of the hitherto running degree programs. Presently though it is being attempted in the same time span, it is becoming a tough task and becoming more strenuous for the students and therefore does not fulfilling the ultimate purpose. A mention of such courses: Value/Moral/Ethics education; value-added education to increase the prospects of career placement and further placement in education in reputed institutes which includes learning of a foreign language (GRE/TOEFL/IELTS have been mentioned above in a different context); appraising the students about the social problems \& evils in the province/state/nation and the world; Anthropogenic activities and climate change and environment (of course full-fledged programs in environmental sciences are available) and in the present context the need to appraise of pandemics. Hence, a suggestion is made to increase the existing duration of the course programs by at least a trimester to accommodate the above. An alternative discussed above is to eliminate the research component from both Bachelors and Master's programs and substitute by the above-mentioned courses.

\subsection{Contents of Course Syllabus and Description and Unbiased Treatment of the Topics}

Because of the freedom every nation and every province 
within the nation and even every university within the province, the contents of the course syllabus and course structure is varied. This variability, can't it be minimised if not eliminated? Why not the same syllabus -as far as possible - throughout the nation and even the world? Then students and educational institutes feel a greater sense of confidence and self-esteem because of greater parity across the world. Mobility across becomes easier. Further, a description of the syllabus may be given in as many details as possible. Say a 3 credit course in a 18 week semester will have 54 instruction hours. Students should be given the details of all the 54 hours right in the beginning. Further, the teachers should not take sides while dealing with the topics though they have the right to have their own individual opinions. Professional responsibility demands so. Hence, wherever it is required the topics have to be discussed from different angles -pros/cons; merits/demerits; advantages /disadvantages; harmful/beneficial effects etc. Different perspectives and relevance of the topics to social problems if any has to be explained to the students without taking sides. Say, for example-GM (genetically modified) crops versus non-GM crops; Chemical technology versus Biotechnology; allopathy versus alternative systems of medicine; energy form different sources -Nuclear, Solar, Wind, Hydro, Thermal etc and in case of faculty of humanities -different economic, social and political theories and sytems of governance, various interpretations of poets and writers etc.

\subsection{Supplementary Instruction Methods and Library-Bibliotheque Facilities}

Access to delivered lectures on the computer and to handouts (printed notes either complete or concise) were two main supplementary instruction methods being followed. (For printed notes, there was/is considerable opposition as they were considered as highly resource depleting and damaging ot he environment). The present Covid pandemic has completely changed the erstwhile scenario. The present scenario has changed, and very likely, the future scenario also may change. For how long and how cannot be predicted right now. Online education /teaching or virtual mode has become the present scenario - not only lectures but including examinations, evaluation, Viva Voce, thesis defense, conferences (called webinars). of course all is nothing so novel because since long GRE/TOEFL exams were/are being conducted and evaluated online at the global level and at the national level many nations were conducting skype interviews, etc. However, a genuine problem in many nations is the lack of uninterrupted electric supply/internet access in every part of the country and the unaffordability of lap/desktops by every student. This problem is more severe in highly populated and/or economically backward nations. Of course, people are used to TV for since long and relatively recently with Youtube, etc. At the complete end of the pandemic, there is a need to collect feedback from everyone to decide the pros and cons of online/virtual education and accordingly take suitable measures for the future.

The above mentioned raises a fundamental question and hope for the future. Why not we make use of the best teachers in the world from reputed institutes? They are anyhow giving lectures in their respective places. Why not we telecast -if not simultaneously or immediately- later their lectures to all the concerned students in the entire world? That would be really an exemplary global philanthropic act in the interest of the entire world. UN/UNESCO can fund this type of activities. If this cannot be done, why not choose the best teachers at the national level and provincial level and telecast the same. But the former suggestion makes the students on par across the nations.

Even before Covid because of Google and proxy servers, libraries/bibliotheques have been reduced to a bad shape particularly in the sense of possessing hard copies of textbooks and journals and attendance by students and teachers. The facility for online access of journals on payment varies. For a large nation like India with a huge number of institutes and a gargantuan number of students, every library/bibliotheque cannot afford it. Further, all standard textbooks of the latest editions may or may not be available, and even if available bulky textbooks are difficult to go through on the computer. Any printout of the entire book that too in the original color is unaffordable. Hence, a full-fledged central library/bibliotheque for the entire province, which can provide both hard copies and as well as online access, need to be established. The libraries/bibliotheques in the respective institutes can procure whatever they can with their limited resources. Local publishers should have an agreement with the original publisher to publish the original textbooks in the same language or in their respective native language at lower prices - maintaining a good quality of paper and binding. Contributions in Science \& Technology come from different countries and in different languages. Hence, every country has to develop different bilingual experts in adequate numbers.

\section{Student Assessment}

\subsection{Variations in Grade Point System}

Student assessment is a parameter of wide variations and complexities. During the British period and a long time PostIndependence as well, only absolute marks obtained by the student out of a total hundred were quoted in the students transcripts. Even today, this is so in many competitive exams for jobs and admission into various programs. Over a period of time, India has switched over to the American system of Grades /Grade point system also called CBCS (Choice Based credit system) as the students in addition ot the major subject has a choice to select courses from other interdisciplinary courses and other extra/transdisciplinary courses purely out of their choice. America has a very long history of grading system. But considerable variations are there not only in America but in India and other countries that have adopted Grading system. Hence, there is a need for uniformity. Apart from that, students and parents insisting on quoting the 
absolute number of marks secured needs to be seriously examined. Author has spent four decades -both as a student and a teacher -in this Grading and Grade point system and has experienced the pain and pleasures of students.

Even in the grading system, the evaluation is initially done in terms of marks and totaled up. Then the total marks are assigned a particularly Grade in terms of different letters/alphabets with or without additional affixes and qualitative description of the performance, then points are calculated on the basis of the number of hours for which the course has been taught (credits), then grade point average for all the courses in the particular trimester/semester and at the end of the program the performance is indicated in terms of Overall/Cumulative GPA (OGPA/CGPA) which is again given a qualitative attribute. The above components mentioned are-unfortunately- highly variable both in the US and other countries and in India. At least it should be uniform within a country and more desirable is a uniformity all over the world. There should not be any problem in ensuring uniformity all over the world and hence must be resorted to.

In India, where there is a huge student population and unimaginably severe competition, even mark difference can make a hell of a difference for the students /candidates appearing for various exams. Grade point system has this serious draw back. As mentioned above, initially, the evaluation is done in marks and totaled up for further conversion into Grades etc. But when you convert back the O/CGPA into marks, it is not possible to get the exact marks secured by the students in the exams! Because, say, students differing anywhere from 5 marks or 9 marks and even as high as 20 marks may be awarded the same Grade! This is the problem. To give the author's own example author has studied in trimester system in two different universities in India -both affiliated to the Land Grants commission (USA). In one university, the system was students getting a maximum O/CGPA of 4 . That is 4.0/4.0 is the maximum that a student can get. But understand the marks versus grading system. The highest is $\mathrm{A}=80$ marks and above; followed by $\mathrm{B}=70-79 ; \mathrm{C}=60-69 ; \mathrm{D}=50-59$ and $\mathrm{F}$ below 50 . and below fifty one might have scored 49 , and another might have scored -theoretically speaking -even zero! That is in other words, 0-49 range are awarded $\mathrm{F}$ and are considered as failed and have to repeat the course. In another university where the author was a student, the grading system has differed in the following respects. $\mathrm{A}=90-100 ; \mathrm{B}=80=89 ; \mathrm{C}=70-79 ; \mathrm{D}=60$ 69 and $\mathrm{F}=59$ and below considered as failed. In other universities in India, there are many more variations and also in the US and other countries. Variations are there in all the above components mentioned, which may be summarised as follows: a) Designation of Grades range from A to $G$ with or without another grade "O" indicating outstanding. Further, the grades $\mathrm{A}$ and $\mathrm{B}$ may be further sub-divided into $\mathrm{A}+, \mathrm{A}$, and A- and similarly so with B. b) Numerically, the points allocated for the grades can vary from 1-9 c) The maximum O/CGPA can vary from 3-9 and even 10. d) qualitative description of the grades and the final O/CGPA can also vary -say, Outstanding, Excellent, Acceptable, Very weak, Weak,
Very Good, Good, Satisfactory, with distinction etc.

Mentioned above is the enormous competition and the deficiency in the Grade Point System -in other words, what has been pointed out is the non-equivalence of Grades and marks obtained by different students, as the same Grade is given to students securing different marks. Their range can differ. This problem becomes far more serious in other sectors in India, and apparently, for the same reason, Grade Point system is not followed. I do not know to what extent this holds good in other countries. Grade point system is not followed in most coveted exams of the state/province and nation. They are termed as "most coveted" because candidates who are successful in these exams form the highlevel beurocracy in state and the nation and rule over everything in association with Politicians. They are also a party to decisions in the academic sector. But they are not evaluated as per the Grades/Grade Point System in their examinations but absolutely on the basis of total marks obtained. In case Grade/Grade Point system is followed here, there will be a revolt all over the country. Why? These exams are a question of life and death for the candidates. As mentioned above, here also evaluation is done initially, and marks are stated. In case they are converted to O/CGPA, converting them back into marks candidates cannot get the exact marks which they have genuinely obtained in their exams. No existing formula works. As there is enormous and severe competition among the candidates for these coveted positions, they expect the ranking to be cent percent perfect. This is possible only if the ranking is displayed on the basis of the total marks obtained by all the candidates. This very logic holds good for the academic sector too. Hence the debate between marks versus Grade point system is still valid [22-24].

\subsection{Pattern of Examinations and Differential Allocation of Marks}

How many exams? How many examiners? What are the various components that should be evaluated / How should be the marks distribution? All these are again variable. For a long time as per the British tradition, the entire hundred marks are meant for only one exam at the end of the academic year, and the paper was evaluated by an external examiner -that is, by a teacher who has not taught to the concerned students. Entirely converse system had been there/is there as per the American Grade point System where all the hundred marks are assessed by the teacher who has taught the course. Presently one can find evaluation systems that are entirely internal and entirely external and partly internal \& partly/mostly external. There can be many components of the evaluation system Viz; quizzes, monthly exams, mid-term exams, and final exams. Further, they may have seminars and assignments. The number of marks allocated to each of these and the pattern of the exam can be again variable. In view of so many exams, the course teacher has to be critical enough in framing the questions for various exams. Some patterns club the practical/experimental component in the same course along with the theory while 
some prefer to separate both the theory and experimental part and offer them as independent courses. The interval between the exams and the weightage given to each of the exams has to be duly decided and uniformity maintained as far as possible.

Apart from the number of exams \& type of exams the pattern of question paper also varies a lot. Say, we have MCQ's (Multiple Choice questions); Questions which have short and medium length answers, and long/essay type questions. These may appear in exams to different extents and apportioning of marks to these type of questions vary. Hence, the assessment pattern is so different across institutions. Hence, the need for consensus for a due and uniform setting of question paper and evaluation.

\subsection{Same Question/Examination Paper for All}

In the province/state and nation where the academic calendar is the same and where the course syllabus is the same, the same question/examination paper may be given in all the Universities/ institutions. (It is recommended that uniform syllabus and uniform calendar may be followed wherever it is possible. It may not be possible for the entire curriculum, but wherever it is possible, uniformity may be maintained. This reflects comparable standards and assessment of students though studying in different places).

\subsection{Time Allotment for Different Exams}

Time limit should not be a criterion for evaluating the students depth of knowledge /ability to answer the given question paper. Duration of time should not be a constraint for the performance of students in the examinations. Adequate time should be given. Students differ in the time taken for reflection and the speed of writing and this matters more for questions demanding long answers. Author long back had a conversation with a Canadian professor Dr. Frank Vella. According to him, a student may take 2-3 times more time to answer a paper compared to the same paper being answered by a competent teacher. Initially, the time limit may be fixed by some such criteria. And even then if some students are not able to complete, they may be given an allowance of time.

\subsection{Assessment of Project Work-Dissertation-Thesis}

Usage of the above terms can vary across the institutions. Thesis term is more common for Ph. D. research component (that is, research work done and finally submitted in a formal document). and is also used for Master's research component. Dissertation term is used both for Master's and $\mathrm{Ph}$. D. research component. As above, they are in a formal document. The term project work is used in different contexts. Ph.D. thesis are evaluated everywhere in qualitative terms, but the terms vary. Say, Highly Commended, Commended, Not Recommended, Excellent, Very Good, Good, Approved, Not Approved etc. It is difficult to say whether examiners are really objective in assessing as above. If so, what criteria have they really followed? It is a relief for the students if a common nomenclature and a simplified procedure is followed. Because there can be a lot of variations in the funds and facilities available in a given lab/institute, and the nature of the project can be different. Hence, grading may be avoided and simply state Recommended or Not Recommended or Approved or Not Approved. Another variation is in the number of external examiners selected and the place where they hail from. While some may prefer only one, some prefer up to three. Where only one is preferred, there is again a variation. The examiner can be from the same province or another province within the nation or outside the nation. The first one mentioned is the most economical. Credence should be given only to the expertise of the examiner. Where two or three examiners are insisted, either all of them can be within the nation or one or two from outside the nation. Any complexity can delay the process and the student may suffer. The entire process must be economical, speedy and credible. Yet another variation is a discretion in selecting one of the external examiners to conduct the defense.

For Master's dissertation/ thesis in India, the practice of both qualitative and quantitative (giving marks out of 100 to 200 ) is there. It is felt by many, including the author, that the evaluation should not be in terms of marks but only in qualitative terms in case of master's dissertation as well. Similarly so for project work also.

A common component in both Master's and $\mathrm{Ph}$. D. thesis is the defense of the thesis and viva Voce by an external examiner. Both closed-door and public/open defense and Viva Voce are practiced. For everyone, it should be an open/ public viva so that fellow students do not feel any discrimination, and all attending also get convinced and spread the message.

\section{Teacher-Student- Administrative Staff Requirement}

Student intake should not be indiscriminate but should be based on manpower requirements in various disciplines/sectors-Say-, Agriculture, Health Care, Defence, Engineering, Arts \& Humanities, General sciences etc. Otherwise, it will lead to poor training, underemployment, unemployment, and thereby the possibility of social unrest, migrations etc. Future prospects of the students must be carefully worked out. Often it is difficult for backward countries/countries with lower economic status to educate even the minimum required people because of the cost of training involved and/or deficiency of an adequate number of experts. Countries are not self-sufficient in producing the various items required for training. Hence, strategies to minimize the cost of training have to be critically analyzed in addition to regulating the intake of the students and accordingly implement the programs. Teacher -Student ratio may vary according to the methodology followed as well. Say, with the help of a mike and slide/screen projection 
facilities, a single teacher can address a large number of students -even as large as in an auditorium. But further tasks like their assessment, conducting practicals/experiments and project works to all etc demands more time and additional manpower and resources. Further, curriculums have become more knowledge-intensive and highly interdisciplinary. so a single teacher cannot deliver the goods. The present times have become an era of specializations and super specializations. Hence, how much amount of work to be allotted to a teacher needs to be worked out without affecting the quality of the training. Accordingly, the teacher-student ratio has to be decided. A strategy to reduce the local burden and also to ensure high standards has been mentioned above. That is having an international agreements to telecast the lectures of other teachers elsewhere. If time zones are very different, re-telecast can be accordingly adjusted.

In what numbers /ratio administrative staff should be in an educational institution is seldom discussed. This is a serious problem in some countries. Problems of over/under the intake of students, teachers, and administrative staff do exist. A large hierarchy in administration is not required. The same number of people can be profitably used otherwise.

\section{Conclusions}

While variations seem inevitable across the nations in the world because of differences in population, economic status, already achieved development in education and science \& technology, attempts should still be made to attain as much uniformity as possible in as many parameters as possible in running the educational programs. The need for it is emphasized. An effort in the above direction definitely reduces the communication gap across the nations and also help in raising the standards of education programs, particularly in backward and low economic status countries. Wherever it is not possible to achieve uniformity across all nations, the attempt should be to achieve uniformity in different continents or within countries. And the least that can be done is to achieve uniformity at least within a province/state of a nation. However, as mentioned above, the goal should be to achieve as much uniformity as possible at all levels.

\section{References}

[1] 10 Countries With The Highest Teachers Salary In The World --https://naibuzz.com/10- countries-with-the-highest-teacherssalary-in- the-world/ (Page Last Updated January, 2, 2020.

[2] Leanna Garfield Shavanne Gal (2018). The best and worst countries to be a teacher, based on salary. (https://www.businessinsider.in/tech/the-best-and-worstcountries-to-be-a-teacher-based-onsalary/articleshow/63885200.cms).

[3] OECD (2018), Teachers' salaries (indicator). doi: 10.1787/f689fb91-en (Accessed on 26 November 2020) https://data.oecd.org/eduresource/teachers-salaries.htm https://en.wikipedia.org/wiki/British_Empire (This page was last edited on 23 November 2020).

[4] https://en.wikipedia.org/wiki/British_Empire. British Empire. (This page was last edited on 23 November (2020).

[5] https://en.wikipedia.org/wiki/British_Raj. British Raj (This page was last edited on 21 November 2020).

[6] https://en.wikipedia.org/wiki/Land-grant_university. Land Grants University (This page was last edited on 14 November 2020).

[7] Mustafa Sutarwala (2019) Understanding the GPA grading scale.

https://www.schoolapply.com/blog/posts/2017/april/gpa-blog/.

[8] https://en.wikipedia.org/wiki/Grading_in_education. Grading in Education (This page was last edited on 8 November 2020).

[9] https://en.wikipedia.org/wiki/Grading_systems_by_country. Grading systems by Country (This page was last edited on 16 November 2020,).

[10] Margie Olivares (20180. The American grading system from A to F and GPA. https://www.mooxye.com/blog/en/americangrading-system-and-gpa/.

[11] https://www.universitiesintheusa.com/blog/2015/july/usuniversity-grading-scale.

[12] https://en.wikipedia.org/wiki/Academic grading in the Unit ed_States. Academic Grading in the United states (This page was last edited on 7 October 2020,).

[13] Brianna Burrows (2020) What is the Difference Between Quarters, Semesters, and Trimesters? https://www.studyusa.com/en/a/1235/what-is-the-differencebetween-quarters- semesters-and-trimesters\#.

[14] The US Higher Education System Explained. https://shorelight.com/student- $\quad$ stories/the-us-highereducation-system-explained/ Last updated on November 16, 2020).

[15] Understanding the American education system. http://www.studyusa.com/en/a/58/understanding-theamerican-education-system (updated August 26, 2020).

[16] Higher Education in Canada. https://en.wikipedia.org/wiki/Higher_education_in_Canada (This page was last edited on 25 September 2020).

[17] Higher education system in Germany http://ecahe.eu/w/index.php/Higher_education_system_in_Ger many\#. Higher education system in Germany - (This page was last modified on 23 May 2017).

[18] The Netherlands Higher education system https://www.euroeducation.net/prof/netherco.htm

[19] Cyranoski, D., Gilbert, N., Ledford, H., Nayar, A., \& Yahia, M. (2011). Education: The PhD factory. Nature, 472 (7343), 276-279. doi: 10.1038/472276a.

[20] Klodjan Staffa,--Why PhDs Should Stop Applying For Postdocs And Start Applying For Research Scientist Positions https://cheekyscientist.com/phds-stop-applying-postdocs-startapplying-research-scientist-positions/

[21] Ashely Murphy (2019) How many years does it take to complete a PhD? https://www.phdstudies.com/article/howmany-years-does-it-take-to-complete-a-phd/\# 
[22] Grading in education-https://en.wikipedia.org/wiki/Grading_in_education page was last edited on 8 November $202 \overline{0}$ ).

[23] How to convert your GPA to a 4.0 scale https://pages.collegeboard.org/how-to-convert-gpa-4.0-scale
[24] https://www.google.com/search?rlz=1C1CHBF enIN913IN91 $3 \&$ source $=$ univ\&tbm $=$ isch $\& \mathrm{q}=$ grade + point + system \&sa $=X \& v$ ed=2ahUKEwj99abwkaDtAhW2ILcAHWwKCBkQjJkEegQI $\mathrm{AhAB}$

[25] Grade system-http://www.kasc.ac.in/examsection/docs/GradeSystem.pdf 